\title{
мaruce Tanares de Onnera' Carta sobre o artigo "Preferências de mulheres brasileiras quanto a mudanças na menstruação"
}

Carta ao editor

Correspondência:

E-mail: tavaresm2002@yahoo.com.br
Recife, junho de 2007.

\section{Ao Editor da RBGO}

Entre os trabalhos originais da RBGO de fevereiro passado, foi publicado excelente artigo de autoria de Carmen Porto Ribeiro, Ellen Hardy e Eliana Maria Hebling, "Preferências de mulheres brasileiras quanto a mudanças na menstruação", cujos argumentos encontram ressonância em autores que defendem a supressão medicamentosa do sangramento menstrual como estratégia que pode ser utilizada pelas mulheres para definir o espaçamento ou até mesmo a interrupção de seus ciclos menstruais ${ }^{1}$.

A despeito dos argumentos utilizados - da inutilidade ou mesmo prejuízo fisiológico produzido por perdas sangüíneas desnecessárias - a investigação traz à baila a discussão inserida no campo do feminismo contemporâneo, acerca do direito das mulheres sobre seus corpos ${ }^{2,3}$, seja na definição da sua função reprodutiva ou na possibilidade de poderem escolher quando, como ou se desejam menstruar.

A experiência acumulada, por meio de estudos clínicos sobre a eficácia na inibição da atividade endometrial e supressão da menstruação por drogas que se inserem sob a categoria de anticoncepcionais - especialmente aqueles com baixas dosagens hormonais ${ }^{4,5}$-, bem como a sua tolerabilidade e a baixa ocorrência de efeitos adversos a médio e longo prazo têm fomentado a idéia sobre a disposição de um arsenal terapêutico seguro, razoavelmente accessível e bem aceito pelas mulheres, como suas usuárias potenciais.

Neste sentido, alguns questionamentos se colocam:

- O quão seguro, a longo prazo, pode ser considerado este método medicamentoso para alterar o fluxo menstrual, já que o mesmo pode, em muito, ultrapassar o tempo de exposição habitual quando do seu uso com fins contraceptivos?

- Qual a relação custo/benefício para as mulheres, seja do ponto de vista financeiro (aquisição de medicamentos por longos períodos) ou da segurança quanto aos efeitos colaterais e reações não previsíveis?
- O risco potencial para a saúde pelo uso prolongado, que pode resultar em prejuízos para a saúde da mulher que a ele se submetesse, seria compensado, a partir da perspectiva das mulheres que o utilizariam, pelo exercício da chamada "liberdade feminina"?

- Ou, ainda, será que a população pesquisada tem conhecimento suficiente dos riscos e benefícios para uma escolha consciente para tomada desta decisão?

A transposição automática de resultados de investigações de base essencialmente quantitativa e com indicações diversas das rotineiramente preconizadas, como a interrupção voluntária da menstruação sem fins contraceptivos, depara-se, entretanto, com limitações tanto de base conceitual quanto metodológica, na medida em que tais estratégias de abordagem não são compreensivas o suficiente para apreender a constituição dos significados da aceitação ou não de tais práticas.

Assim, diferentes apreensões do processo saúde-doença nas concepções populares, relacionadas ao ciclo vital, são concebidas como sinal de saúde - a menstruação - ou como doenças normais da idade - como reumatismo e hipertensão nos idosos, tal como referido pelas autoras do artigo em apreço, quanto aos resultados provenientes de estudo de base qualitativa: “...em estudo qualitativo, desenvolvido por nosso grupo de pesquisa. Neste estudo, observou-se que as mulheres valorizavam a menstruação, como sinal de saúde e normalidade, e que temiam que a sua falta fosse sinal de algum tipo de anomalia" (p. 77).

Embora partilhemos da idéia de que não existe qualquer conflito fundamental na utilização de métodos quantitativos e qualitativos ${ }^{6-8}$, sendo, inclusive, necessário, muitas vezes, a utilização de ambos no processo de geração de teoria sobre determinado tema, avaliamos que o aprofundamento do hiato existente entre estas abordagens parece relacionado primordialmente à não observância das potencialidades e limitações de cada uma delas em particular.

Desta forma, ressaltamos como não suficientemente fundamentada, no estudo em questão, a afirmação de que 
"nossos resultados dão apoio à nova proposta de que regular a menstruação, com outros intervalos, poderia também ser bem aceita por uma parte das potenciais usuárias. Isto se consegue com particular eficácia com a pílula de ciclo longo, habitualmente de três meses. Provocar amenorréia com métodos anticoncepcionais de longa duração com progestágeno puro já não é tão consistente.” (p.78), na medida em que, pela análise dos objetivos e resultados apresentados neste artigo, tais aspectos não foram investigados. Ademais, pelo fato do estudo incorporar, de forma proporcional, mulheres em grupos de idade (18-20, 25-34 e 45-49 anos), e anos de escolaridade ( $<8$ anos e $>12$ anos) diferentes, frustrounos a expectativa de análise dos resultados controlados por estas variáveis, já que o nível de escolaridade e o fato de pertencer a coortes de idade diferentes (mulheres que nasceram em plena era da chamada "revolução sexual", junto a outras para as quais as conquistas feministas já se encontravam bem mais consolidadas) pode exercer impacto diferente sobre as respostas às questões de pesquisa investigadas.
Por outro lado, mais uma vez, gostaríamos de enfatizar a riqueza da temática de pesquisa enfocada pelas autoras cujo estudo, ora analisado, também contribui para o debate do tema na busca de evidências para apreensão da existência ou não de sensibilização ao uso de drogas anticoncepcionais para prolongamento do período menstrual pelas mulheres e, ao mesmo tempo, concordar com elas quanto ao fato de que "a motivação das mulheres parece corresponder a um processo mais complexo, que forma parte do conceito de que a mulher já não é mais obrigada a cumprir com funções biológicas como engravidar, dar à luz, amamentar e engravidar novamente durante toda sua vida fértil. Liberar-se dessa função biológica, obrigatória para nossas antepassadas, foi uma das grandes conquistas da chamada "liberação feminina". Aparentemente, liberar-se da "obrigação" de menstruar vem a ser como uma segunda etapa dessa liberação de condicionantes biológicos típicos de ser mulher" (p.78).

Atenciosamente, Marluce Tavares de Oliveira

\section{Referências}

1. Nelson AL. Extended-cycle oral contraception: a new option for routine use. Treat Endocrinol. 2005;4(3):139-45.

2. Osis MMD. Paism: um marco na abordagem da saúde reprodutiva no Brasil. Cad Saúde Pública. 1998;14 Supl 1:25-32.

3. Giffin KM. Nosso corpo nos pertence: a dialética do biológico e do social. Cad Saúde Pública. 2002;7(2):190-200.

4. Baracat EC, Barbosa IC, Campos AA, Hyppolito SB, Melo NR, Mussielo R, et al. Avaliação da tolerabilidade e do controle de ciclo de dois contraceptivos orais de baixa dose: estudo comparativo aberto. Rev Bras Ginecol Obstet. 1998;20(5):273-80.

5. Paula TBC, Moron AF, Guazzelli C, Nonoyama K, Salzone CM Efeitos dos contraceptivos hormonais orais de baixa dosagem estrogênica nas taxas de folato intra-eritrocitário. Rev Bras Ginecol Obstet. 2003;25(7):475-9.

6. Turato ER. Métodos qualitativos e quantitativos na área da saúde: definições, diferenças e seus objetos de pesquisa. Rev Saúde Pública. 2005;39(3):507-14.

7. Minayo MCS. O desafio do conhecimento: pesquisa qualitativa em saúde. $8^{a}$ ed. São Paulo: Hucitec; 2004.

8. Oliveira CD. O papel da inovação no processo da estratégia: uma pesquisa qualitativa em empresas emergentes de base tecnológica no Brasil [tese]. Rio de Janeiro: Universidade Federal do Rio de Janeiro; 2003.

ELLEN HARDY

Resposta do autor

Campinas, 20 de junho de 2007.

Prezado Dr. Jurandyr,

Agradecemos o interesse da Dra. Marluce Tavares de Oliveira que analisa com tanto cuidado nosso ar- tigo $^{1}$. Para maior clareza, tentaremos responder seus questionamentos ponto a ponto.

1. Os quatro primeiros questionamentos da doutora Oliveira referem-se à segurança e ao custo do uso de medicamentos para regular o fluxo menstrual por tempo prolongado. $\mathrm{O}$ trabalho refere-se ao 
uso de hormônios como anticoncepcionais que poderiam também regular o ciclo menstrual. $\mathrm{O}$ uso prolongado de métodos hormonais em forma continua é assunto que tem sido objeto de pesquisas e escapa ao objetivo do nosso estudo $^{2}$. De toda forma, o tempo de avaliação de uso contínuo de métodos anticoncepcionais hormonais é ainda escasso e são necessários mais dados para poder assegurar que não trazem nenhum risco para a saúde.

2. Não entendemos a frase "A transposição automática de resultados de investigações de base... quantitativa e com indicações diversas das... preconizadas, como a interrupção voluntária da menstruação, sem fins contraceptivos."

Novamente, insistimos que, no trabalho, não foi indicada "a interrupção voluntária da menstruação, sem fins contraceptivos." Se "transposição automática" se refere à extrapolação ao universo de nossos resultados, deixamos claro, na página 78, que isso não é possível, tanto pelas razões aduzidas pela doutora Oliveira quanto pela limitação geográfica e numérica da amostra.

3. Compartilhamos os conceitos da doutora Oliveira nos três parágrafos seguintes. A frase de nosso trabalho a que faz referência corresponde a um outro estudo com outra população, totalmente independentes da que estamos apresentado e que não tem contradição real com os deste estudo.
4. Discordamos que não está suficientemente fundamentado no estudo que os "resultados dão apoio à proposta de que regular a menstruação com outros intervalos poderia ser bem aceita por uma parte das potenciais usuárias (de anticoncepcionais)." Não é possível ignorar que apenas $23,5 \%$ das mulheres manifestaram preferir menstruações mensais e que $40 \%$ gostariam de ter intervalos mais prolongados. É difícil não concluir que esse resultado sugere fortemente que muitas mulheres vão aceitar "a pílula de ciclo longo, habitualmente de três meses".

5. Referente aos grupos etários e à escolaridade, foram justamente escolhidos para evitar que os resultados fossem enviesados se, por acaso, incluísse apenas determinado grupo etário ou de escolaridade. Se o tamanho amostral pudesse ter sido muito maior, evitaria-se a necessidade de escolha de grupos específicos; entretanto, essa possibilidade estava fora dos recursos disponíveis.

Terminamos agradecendo a concordância com nossa apreciação referente à motivação das mulheres no último parágrafo de sua carta.

Atenciosamente,

Profa. Dra. Ellen Hardy

Departamento de Tocoginecologia

FCM/ UNICAMP

\section{Referências}

1. Ribeiro $C P$, Hardy $E$, Hebling EM. Preferências de mulheres brasileiras quanto a mudanças na menstruação. Rev Bras Ginecol Obstet. 2007; 29(2):74-9.
2. Meirik O, Farley TM, Sivin I. Safety and efficacy of levonorgestrel implant, intrauterine device, and sterilization. Obstet Gynecol. 2001 ; 97(4):593-547. 